\title{
Effect of Ti and TiC alloyants on the mechanical properties of W-based armour materials
}

\author{
E. Tejado, A. Martin, J.Y. Pastor \\ Departamento de Ciencia de Materiales-CIME, Universidad Politécnica de Madrid, C/ Profesor Aranguren 3, E28040, Madrid, Spain
}

The main requirements of tungsten materials for structural divertor applications comprise properties like high thermal conductivity, high-temperature strength and stability, high recrystallization temperature, and enough ductility for an operation period of about two years under massive neutron load [1]. However, the mechanical properties of tungsten commercial products are still one of the main concerns for their use in structural armour applications. With the aim of improving this aspect, two W/Ti based products are presented in this paper: (1) a W-Ti alloy with a Ti solid solution and (2) an UFG microstructure product with TiC dispersed particles; both with the aim of obtaining a suitable fusion armour material with enhanced properties, especially at very high temperatures when pure tungsten suffers strong thermal degradation.

It has been reported that strength and recrystallization control can be improved with dispersed TiC particles which inhibits the grain growth. Furthermore, both flexural strength and fracture toughness were twice and even three times higher than the ones observed for our reference pure tungsten pro-duced by the same group and technique, which is, indeed, a great success. However, the intrinsic brit-tleness of tungsten cannot be enhanced by particle dispersion or solid solution with Ti. On the contrary, intergranular rupture is enhanced even more, and the DBTT is even higher than that of pure $\mathrm{W}$.

Keywords:

Tungsten alloys

Titanium alloyants

Plasma-facing-material

Ductility

Thermo-mechanical properties

1.

\section{Introduction}

In comparison to the ITER design $(Q=10)$, the requirements of electricity generation and tritium self-sufficiency in the DEMO and beyond lead to significant challenges in the selection of the materials. DEMO will have significantly higher values of fusion power, plasma density, temperature across the whole profile, fuelling rate and core radiation fraction [2]. At present, the European DEMO reactor design has not been formally selected, and the detailed operational requirements are not yet available [3]. However, the different proposals cluster around a vessel radius of around $7.5 \mathrm{~m}$ and fusion power of almost $1 \mathrm{MW}$ (2-3 MW theoretical), determined by the energy confinement and divertor protection, and by internal electrical power needed to run the plant [4].

Both the blanket system and the divertor are among the most challenging components of the machine. Indeed, they will cover an area of about $830 \mathrm{~m}^{2}$ in ITER and even larger in DEMO. As the first wall, they will be subjected to high heat fluxes (HHF) of plasma particles and electromagnetic radiation. Since they should resist this harsh reactor environment during several years of operation, materials selection and design of plasma-facing components (PFCs) remain significant challenges in the safe and reliable operation of the nuclear reactors.

Tungsten is uniquely suitable for the armour due to its high melting point $\left(3410^{\circ} \mathrm{C}\right)$, high threshold energy for sputtering (around $100-200 \mathrm{eV}$ for $\mathrm{H}$ isotopes) and retention of tritium, and relatively high thermal conductivity at room temperature $\left(174 \mathrm{~W} \mathrm{~m}^{-1} \cdot \mathrm{K}^{-1}\right)$ [5]. For these reasons, it is the baseline material for the state-of-the-art plasma-facing component technology [6]. But several risks are associated with the use of tungsten. Tungsten has a body-centred cubic (BCC) crystal structure so there are few slip planes and a propensity for brittle fracture as its DBTT is around $400^{\circ} \mathrm{C}$, even in an unirradiated state. As a structural material, both the DBTT and the fracture toughness are key issues. The fracture toughness of polycrystalline tungsten at RT is quite low, in the region of $10 \mathrm{MPa} \mathrm{m}^{1 / 2}$. In addition, $\mathrm{W}$ shows a strong tendency to recrystallization at temperatures well below its melting point [7]. 
Furthermore, it has been reported that crack formation and recrystallization can occur in a $\mathrm{W}$ monoblock due to the cyclic heat load relevant to ITER [8]; these cracks can result in the brittle destruction which is a hazard for the full tungsten divertor. As a result, the temperature window of $\mathrm{W}$ is between $500^{\circ} \mathrm{C}$ and $1200^{\circ} \mathrm{C}$, for radiation embrittlement and recrystallization temperatures, respectively. In DEMO, neutron irradiation will be more critical for materials than in ITER. Radiation generates lattice defects and He bubble production by transmutation in the PFM leading to embrittlement and reduced thermal conductivity [9].

Another drawback of tungsten is its strong reactivity in air, potential oxidation/deflagration could occur in a loss of coolant accident with simultaneous air ingress into the vacuum vessel. This accident would involve temperatures of the components above $1000^{\circ} \mathrm{C}$ because of the decay heat, though self-passivating tungsten alloys have been developed in the last years, and considerable progress has been made in this regard with $\mathrm{W}-\mathrm{Cr}-\mathrm{Y}$ alloys [10].

Considering these limitations, further enhancements of the properties of $W$ are essential before its commercial use. Mechanical properties of $\mathrm{W}$ are a function of the production history, alloying elements, purities, and thermomechanical treatments [11], thus various strategies have been followed for its modification and improvement.

The addition of certain elements, such as rhenium, technetium, titanium or cobalt [12] can improve the ductility of W thereby reducing the DBTT of the alloy. Research by Ref. [13] observed a decay of the DBTT when iridium was added in solid solution, but cost limitations inhibit their use in the reactor. Rhenium is known to enhance the ductility of $\mathrm{W}$. The addition of $\sim 5 \mathrm{wt} \%$ Re by solid solution reduces the DBTT of $\mathrm{W}$ by $\sim 300^{\circ} \mathrm{C}$ [12], but its use for fusion applications is excluded because of neutron activation issues, cost, reduced thermal conductivity, and radiation-induced intermetallic phases, that produce hardening and embrittlement. Re atoms in the $\mathrm{W}$ crystal structure result in a transition to an asymmetric dislocation core and a reduction of the Peierls stress [14], though similar effects could be obtained by alloying with tantalum, vanadium, molybdenum or even titanium, since they also form solid solution with W.

On the other hand, materials with an ultrafine-grained (UFG) microstructure usually exhibit enhanced ductility, as stated by Yin et al. [15] where different lab-scale tungsten grades exhibited large uniform elongation when tensile-tested up to $600^{\circ} \mathrm{C}$. Besides, it would be expected that a UFG microstructure improves the irradiation resistance of $\mathrm{W}$, as grain boundaries can be strong sinks for the radiation-induced defects. The improvement of the fracture toughness through grain size engineering has been investigated extensively. For example, W-doped with potassium or $\mathrm{W}-\mathrm{La}_{2} \mathrm{O}_{3}$ produced via severe plastic deformation (SPD) with grain sizes $\sim 300 \mathrm{~nm}$ showed an increase in fracture resistance at low temperatures [16,17], but they are yet not suitable for producing industrial-scale semi-finished products. Therefore, powder metallurgical routes, i.e. mechanical alloying and hot isostatic pressing (HIP), even not producing semi-finished products, are still the preferred ways in the industry. Furthermore, the maintenance of a UFG microstructure, with the dispersion of hard particles such as $\mathrm{La}_{2} \mathrm{O}_{3}, \mathrm{Y}_{2} \mathrm{O}_{3}$ or $\mathrm{TiC}$ may have the capability of inducing grain refinement, and they could even act as sinks to capture radiationinduced defects, thereby improving radiation resistance as well [18]. Furthermore, second-phase particles can inhibit recrystallization by hindering the sliding of grain boundaries and stabilizing the microstructure at higher temperatures [19]. However, in spite of their small grain sizes, research by Refs. [20,21] of HIP alloys with $\mathrm{Y}_{2} \mathrm{O}_{3}$ and $\mathrm{La}_{2} \mathrm{O}_{3}$ particles demonstrated to enhance the brittleness at moderate temperatures.

Tungsten materials are usually fabricated by powder metallurgy routes, where the mechanical milling is a critical step for alloying and developing a nanostructured material. Later sintering is performed by hot isostatic pressing (HIP), however, entirely consolidation is hard to achieve due to the elevated melting point of W. In this regard, several research works have shown that Ti is a sintering activator for the $\mathrm{W}$ alloys [22]. The solubility in $\mathrm{W}$ is total for a weight percent of Ti below 10\% [23]. Furthermore, it has been reported that Ti addition might alter the core structure of the screw dislocations and their slip mechanism, increasing W ductility [24].

Therefore, the scope of this research is to examine the thermomechanical performance of divertor armour materials, with special focus on the influence of both microstructure and chemical composition on the fracture behaviour. These materials include $\mathrm{W}$ $2 \mathrm{wt} \% \mathrm{Ti}$ and $\mathrm{W}-1 / 5 \mathrm{wt} \% \mathrm{TiC}$ produced by powder metallurgy and later consolidated by HIP. To better evaluate the influence of the processing parameters, these were modified for each material with the following aims:

- For $\mathrm{W}-2 \mathrm{Ti}$, the goal was to achieve the proper Ti alloying in $\mathrm{W}$, while maintaining a refined microstructure. To achieve it, two W-2Ti products were produced with different milling times: $20 \mathrm{~h}$ and $75 \mathrm{~h}$.

- For W-1TiC and W-5TiC the purpose was to achieve a good dispersion of the $\mathrm{TiC}$ nanoparticles in the $\mathrm{W}$ matrix, inhibiting the grain growth.

\section{Materials and methods}

The $\mathrm{W}$ alloys presented in this study were manufactured and consolidated by Carlos III University (Leganés, Spain). Even through the manufacturing process was not directly included in this study, it deserves mentioning as it strongly affects many of the properties to be explored. This process consisted of:

1. Blending of the base $\mathrm{W}$ powder (99.95\% purity, median particle size $1 \mu \mathrm{m}$ ) with the alloying element in a Tubular T2F mixer for $4 \mathrm{~h}$.

2. Mechanical alloying of the blends at $150 \mathrm{rpm}$ in a high-energy planetary ball mill under a high purity Ar atmosphere. Tungsten carbide (WC) balls of $\varnothing 10 \mathrm{~mm}$ with a 4:3 ball-to-powder ratio inside a sealed WC vessel were used as grinding media. The milling time was set for each composition varying from $20 \mathrm{~h}$ to $75 \mathrm{~h}$ for the $\mathrm{W}-2 \mathrm{Ti}$ alloy, as presented in Table 1.

3. Encapsulation in a steel container and degassing for $24 \mathrm{~h}$ at $400^{\circ} \mathrm{C}$ in MPa in low vacuum $\left(\sim 2 \times 10^{-3} \mathrm{mbar}\right)$.

4. Consolidation by HIP for $2 \mathrm{~h}$ at $1200^{\circ} \mathrm{C}$ and $195 \mathrm{MPa}$ with high purity Ar.

The producers measured the oxygen content of the materials during the different fabrication steps by inert gas fusion infrared detection (LECO Corporation, St. Joseph, Michigan, USA).

Cylindrical bullets of $30 \mathrm{~mm}$ in diameter and $50 \mathrm{~mm}$ in length were obtained after consolidation by HIP. Miniaturized bend specimens (nominal dimensions $1.7 \times 1.7 \times 25 \mathrm{~mm}^{3}$ ) were produced by refrigerated electro-discharge machining to comply with the needs of mechanical testing. Results have been compared with pure tungsten, processed by the same group and metallurgical route, as a reference material [25].

The mechanical behaviour of the HIP materials was then evaluated; proof flexural strength and fracture toughness were obtained by performing non-standard three-point bending (TPB) tests. These were conducted in both oxidizing and vacuum atmospheres and at a temperature range between $25^{\circ} \mathrm{C}$ and $1200^{\circ} \mathrm{C}$. Two to three samples were used for each material and each 
Table 1

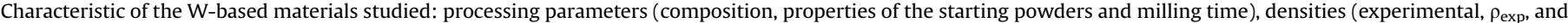

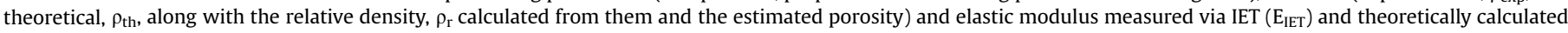
(Eth).

\begin{tabular}{|c|c|c|c|c|c|c|c|c|c|c|c|}
\hline \multirow[t]{2}{*}{ Material } & \multicolumn{2}{|l|}{ Composition } & \multicolumn{2}{|c|}{ Starting powders } & \multirow{2}{*}{$\frac{\text { Mechanical alloying }}{\text { Milling time }(\mathrm{h})}$} & \multicolumn{4}{|l|}{ Density } & \multicolumn{2}{|c|}{ Elastic modulus } \\
\hline & Alloying elements & (wt\%) & Purity (\%) & Avg. Particle size $(\mu \mathrm{m})$ & & $\rho_{\exp }\left(\mathrm{g} / \mathrm{cm}^{3}\right)$ & $\rho_{\text {th }}\left(\mathrm{g} / \mathrm{cm}^{3}\right)$ & $\rho_{\mathrm{r}}\left(\mathrm{g} / \mathrm{cm}^{3}\right)$ & Porosity (\%) & $\mathrm{E}_{\mathrm{IET}}(\mathrm{GPa})$ & $\mathrm{E}_{\text {th }}(\mathrm{GPa})$ \\
\hline W & & & 99.9 & 12 & 20 & $17.64 \pm 0.02$ & 19.25 & 91.64 & 8.36 & $338 \pm 5$ & 400 \\
\hline W-2Ti & $\mathrm{Ti}$ & 2 & 99.9 & $<100$ & 20 & $17.98 \pm 0.04$ & 18.08 & 99.45 & 0.55 & $371 \pm 8$ & 378 \\
\hline & & & & & 75 & $17.60 \pm 0.03$ & & 97.34 & 2.66 & $381 \pm 1$ & \\
\hline W-1TiC & $\mathrm{TiC}$ & 1 & 99 & 0.04 & 50 & $17.23 \pm 0.05$ & 18,19 & 94.69 & 5,31 & $354 \pm 2$ & 403 \\
\hline W-5TiC & & 5 & 99.9 & $<2$ & 70 & $16.15 \pm 0.04$ & 16,81 & 96.10 & 3,90 & $381 \pm 4$ & 407 \\
\hline
\end{tabular}

temperature to ensure test repeatability. The flexure stress was computed based on simple beam theory, however, when elastic regime is exceeded, and plastic deformation occurs, yield strength $\sigma_{\mathrm{y}}$, as determined using the 0.002 strain offset method, was represented in the graphs. Vacuum atmosphere tests were performed inside a vacuum camera furnace with $\mathrm{W}$ heating resistances fully refrigerated, coupled (Sigmatest Materialprüftechnik $\mathrm{GmbH}$, Wedel, Germany) to an Instron 8501 Universal testing machine (Instron, High Wycombe, United Kingdom) with alumina bars for bending/compression testing. It was operated at pressures of about $10^{-6} \mathrm{mbar}$, and between 400 and $1200^{\circ} \mathrm{C}$ of temperature. The heating rate was $30^{\circ} \mathrm{C} / \mathrm{min}$ and once the set point was reached the heating was held during $10 \mathrm{~min}$ for the thermal stabilization of the system before testing. Materials were also tested in an air atmosphere in the temperature range between $25^{\circ} \mathrm{C}$ and $1200^{\circ} \mathrm{C}$, in $200^{\circ} \mathrm{C}$ steps. A small silicon carbide furnace with Eurotherm MTS 653 controller (MTS Systems Corporation, Eden Prairie, MN, USA), mounted inside the loading zone of an Instron 3369 servomechanical universal testing machine (Instron, High Wycombe, United Kingdom), was used for heating the specimens at $30^{\circ} \mathrm{C} / \mathrm{min}$ and testing them at high temperature. Two thermocouples were attached close to the opposite ends of the samples to control the temperature of both specimens and furnace in the oxidizing atmosphere environment. Since the thermal mass of the furnace was much higher than specimens' one, no noteworthy temperature gradients were reported.

Bending test configuration was also used to determine the fracture toughness in the plane $\left(\mathrm{K}_{\mathrm{IC}}\right)$ of the specimens, i.e. the resistance of material to the propagation of a crack. The fracture toughness is measured by loading a sample containing a deliberately introduced crack of length and recording the stress at which the crack propagates. Cracks were introduced using a femto-second laser in the bottom of the bars, as explained by Palacios [26]. With the laser technique, real cracks types with no melted layer (or heat affected layer) in the surrounding of the notch, have been obtained. Overall notch lengths were measured under the scanning electron microscope; yielding mean tip radius between 1 and $50 \mathrm{~nm}$ and laser notches of around $250 \mu \mathrm{m}$. The critical stress intensity factor, for mode I stress in SELNV specimens was then computed from the critical load and the beam section using the equations proposed by Pastor and Guinea $[27,28]$.

For microstructure and fractography examination of postmortem specimens, a Field Emission Scanning Electron Microscope (FESEM) from Auriga Series (Zeiss, Oberkochen, Germany) was used. In addition, basic characterization, i.e. density and elastic modulus measurements were performed. In the first case, the experimental densities ( $\rho_{\text {exp }}$ ) of the materials were determined via the Archimedes method; theoretical densities $\left(\rho_{\text {th }}\right)$ were calculated using the density of each component and the rules of mixtures, where densities of tungsten, titanium carbide and titanium were, respectively, $19.25 \mathrm{~g} / \mathrm{cm}^{3}$ [11], $4.93 \mathrm{~g} / \mathrm{cm}^{3}$ and $4.54 \mathrm{~g} / \mathrm{cm}^{3}$, from reference values [29]. Based on these results, relative density $\left(\rho_{r}\right)$ was determined to obtain the porosity of the materials. Toguether with.

\section{Results and discussion}

\subsection{Microstructure}

The surface morphology of the strengthened/stabilized materials, i.e. these containing $\mathrm{W}-1 \mathrm{TiC}$ and $\mathrm{W}-5 \mathrm{TiC}$ are presented in Fig. 1. The results show that strengthening particles, mostly existing at grain boundaries (black areas, confirmed by EDS-mapping and XRD analysis), inhibit the growth of tungsten grains (grey areas) during the sintering process; as a result, the refinement of the microstructure is higher for W-5TiC. Black areas in the.

In both materials, but especially in $\mathrm{W}-5 \mathrm{TiC}, \mathrm{W}$ phase exhibits roughly bimodal grain size: large grains of several microns as well as areas with submicron grains. Besides, TiC aggregates can be observed in both microstructures. The aggregation probability of TiC particles is relatively high due to their covalence chemical bond characteristics, therefore, the accumulation of TiC particles at $\mathrm{W}$ grain boundaries occurs [30].

The densification achieved for both materials, together with the data provided for reference pure $\mathrm{W}$ material, manufactured by the same route and conditions, are summarized in Table 1 . It can be observed that addition of TiC decreases density since the density of $\mathrm{TiC}\left(4.93 \mathrm{~g} / \mathrm{cm}^{3}\right)$ is lower than that of tungsten $\left(19.2 \mathrm{~g} / \mathrm{cm}^{3}\right)$. According to this table, the relative density of $\mathrm{W}$-TiC materials also increases with increasing $\mathrm{TiC}$ content. It indicates that $\mathrm{TiC}$ is beneficial to sintering and densification of composites to a certain extent, up to this percentage, TiC particles tend to aggregate, lowering the densification [30]. However, the increased MA time could be co-responsible of this densification. The elastic modulus increases as well with the increase in TiC content, hence the addition of $\mathrm{TiC}$ improves the elastic modulus and hardness of the composites. This increase in elastic modulus is indeed due to the direct contribution of the high elastic modulus of $\mathrm{TiC}$ as compared to the one of pure tungsten.

In the case of solid solution materials, i.e. W-2Ti, the estimation of grain size could only be made by observation of the fracture
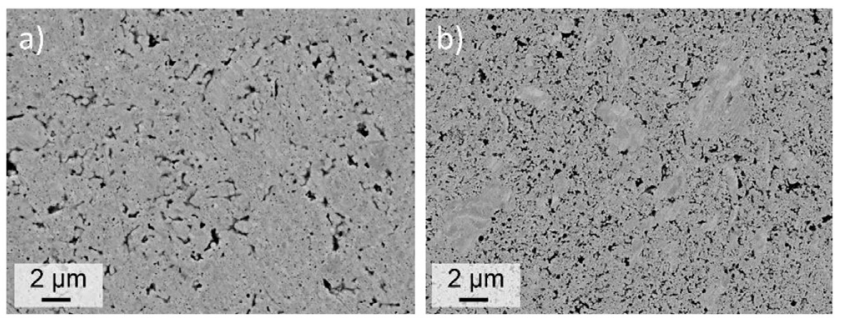

Fig. 1. Scanning electron micrographs of a polished section of (a) W-1TiC and (b) W5TiC showing the details of the microstructure. Grey areas indicate $\mathrm{W}$-rich phase while black ones indicate $\mathrm{TiC}$ rich areas. 


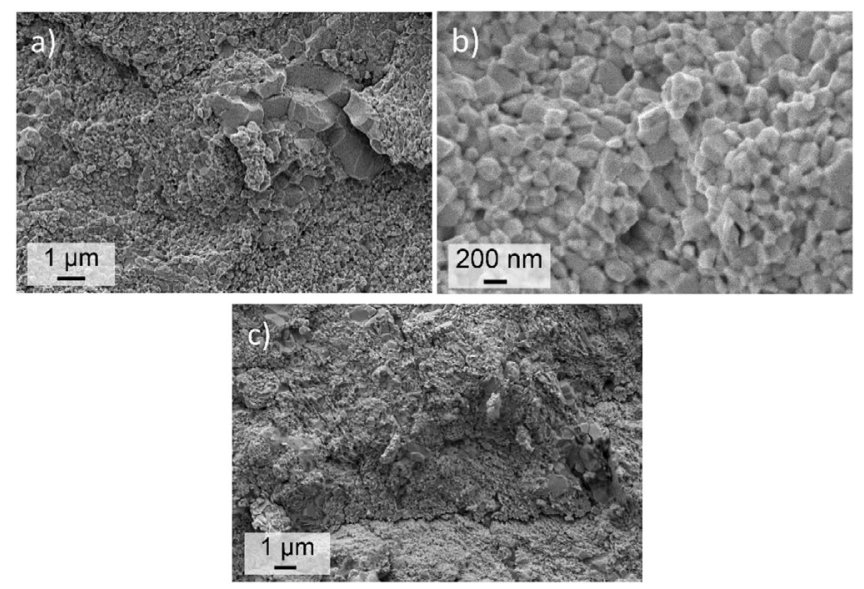

Fig. 2. SEM fracture morphologies of $\mathrm{W}-2 \mathrm{Ti}$ with (a) and (b) $20 \mathrm{~h}$ milling time and (c) $75 \mathrm{~h}$ milling time, both tested at $25^{\circ} \mathrm{C}$.

surfaces after testing at room temperature (Fig. 2). In these images, the role of the milling time on the morphology and grain size can be easily evaluated. Fig. 2a revealed the presence of large tungsten particles that may not have been totally ground, as starting particle size is $\sim 12 \mu \mathrm{m}$. These polyhedral coarse $\mathrm{W}$ grains are surrounded by nanometric rounded grains of the $\beta(\mathrm{W}-\mathrm{Ti})$ solid solution, as observed in Fig. 2b where a higher magnification SEM image is presented. $\beta(\mathrm{W}-\mathrm{Ti})$ solid solution was produced because of $\mathrm{Ti}$ diffusion along the grain boundaries of $\mathrm{W}$ during sintering, revealing a bimodal grain morphology.

On the other hand, the microstructure observed in Fig. $2 \mathrm{c}$ is more homogeneous, as faster grain refinement has been obtained after $75 \mathrm{~h}$ of MA. Sparse W grains of $250-500 \mathrm{~nm}$ can still be spotted, though $\beta(\mathrm{W}-\mathrm{Ti})$ solid solution is the predominant phase.

In contrast to the observed for $\mathrm{W}-4 \mathrm{wt} \% \mathrm{Ti}$ materials $(\mathrm{W}-4 \mathrm{wt} \% \mathrm{Ti}$ and $\mathrm{W}-4 \mathrm{wt} \% \mathrm{Ti}-0.5 \mathrm{wt} \% \mathrm{Y}_{2} \mathrm{O}_{3}$ ) manufactured by the same metallurgical route [21], Ti seems to be totally dissolved in the $\beta(\mathrm{W}-\mathrm{Ti})$ phase. Aguirre reported the presence of elongated lagoons of titanium, where no tungsten atoms diffusion was observed. The author suggested that the consolidation HIP treatment might produce the segregation of Ti into large pools sparsely distributed in the corresponding alloy, even though the solubility of $\mathrm{Ti}$ in $\mathrm{W}$ is much higher.

However, a later study performed by Jahangiri [31] on the effects of MA and Ti content on the effective lattice parameter, crystallite size and lattice strain of $\mathrm{W}$ with different fractions of Ti, proved that
Ti-phase was still present for alloys containing $4 \mathrm{wt} \% \mathrm{Ti}$, as the calculated solubility of Ti for this alloy was $1.78 \mathrm{wt} \%$ (6.5 at\%) after $10 \mathrm{~h}$ milling time. Furthermore, they observed that with the increase of MA duration, so does the solubility of Ti. However, despite the advantages of increasing the MA time on Ti dissolution, it should be noted that these effects are narrowed by the oxygen contamination of the alloy. Fig. 3a illustrates the oxygen content in the powders as a function of the milling time.

Although the powder handling and milling were carried out under a high purity Ar atmosphere, the presence of oxygen in the powders was evident. Fig. 3a shows a continuous increase of the $\mathrm{O}_{2}$ determined by Savoini and co-authors [32]. After $20 \mathrm{~h}$ of milling, the oxygen content of the $\mathrm{W}-2 \mathrm{Ti}$ blend was $0.35 \mathrm{wt} \%$, while it reached $0.7 \mathrm{wt} \%$ after $75 \mathrm{~h}$. However, it should be highlighted that the initial $\mathrm{O}_{2}$ content of the elemental $\mathrm{W}$ and Ti powders was $0.04 \%$ and $0.07 \%$, respectively. The milling effect on the XRD patterns, i.e. of the average crystallite size and lattice strain, was also calculated by them and shown in Fig. 3b. The cumulative grain refinement for $\mathrm{W}-2 \mathrm{Ti}$ is in accordance to the observed in the SEM fractographic images (Fig. 2). It indicates that at least $50 \mathrm{~h}$ of milling, at the present conditions, are required for getting grain refinement with average crystallite size of $\sim 20 \mathrm{~nm}$ for $\mathrm{W}-2 \mathrm{Ti}$. Consequently, a compromise milling time for constraining the $\mathrm{O}_{2}$ contamination, while achieving the suitable homogenization and refinement, should be stated. However, as observed in Table 1, with the increase in milling time and homogenization, so does the porosity and the elastic modulus follows the same trend, though this latter could be due to the refinement of the grain size.

\subsection{Mechanical properties}

The TPB test results for the flexural strength of the $\mathrm{W}$-2Ti materials showed that the alloyed behaviour was linearly elastic until fracture at almost all studied temperatures. But, at $1200{ }^{\circ} \mathrm{C}$ under vacuum, the samples exhibited plastic deformation without breaking. In this case, the $0.2 \%$ yield strength offset was represented using dashed lines (Fig. 4).

Increasing the milling time increased, as well, the flexural strength across the entire temperature range. Moreover, results for $\mathrm{W}-2 \mathrm{Ti}$ after $75 \mathrm{~h}$ MA are $40 \%$ higher than for $\mathrm{W}-2 \mathrm{Ti}$ after $20 \mathrm{~h}$ MA, and even 4 times greater than those of reference pure $W$. The evolution of the bending strength with temperature is quite similar for the three materials represented: strength is almost constant with temperature, with no clear influence of the atmosphere. Above $800^{\circ} \mathrm{C}$ values decreased due to thermal degradation. At $1200^{\circ} \mathrm{C}$, the properties had completely degraded even under a
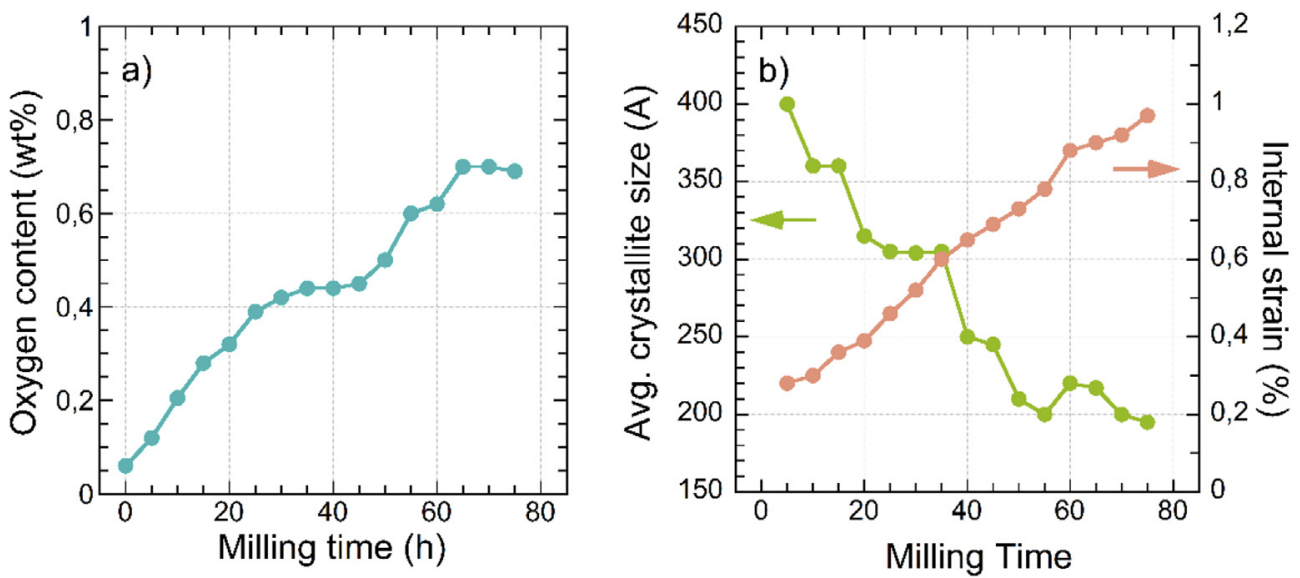

Fig. 3. (a) Oxygen content versus milling time for W-2Ti blends; (b) Effect of milling time on the average crystallite size and internal strain of the W-2Ti powders [32]. 


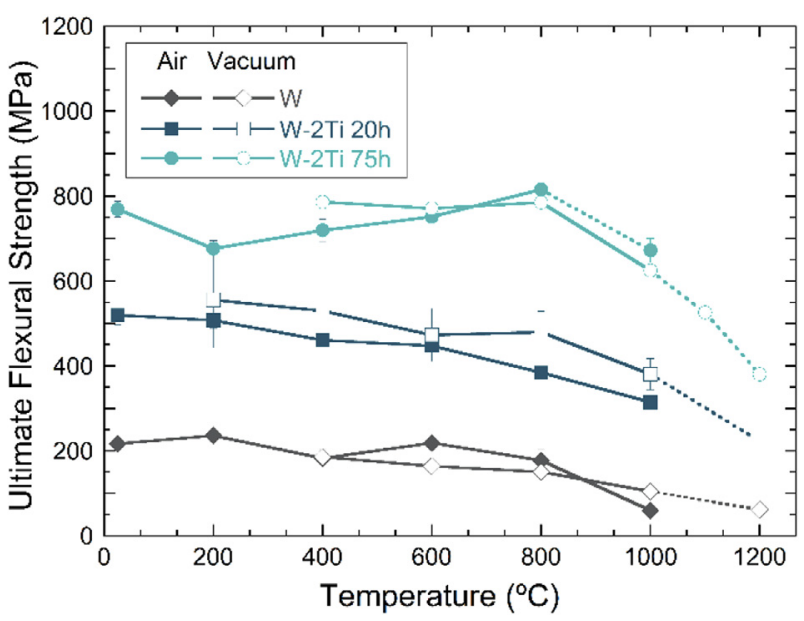

Fig. 4. Average flexural strength versus test temperature for the $\mathrm{W}-2 \mathrm{Ti}$ alloys and pure $\mathrm{W}$ in air and under vacuum. The dashed lines represented the yield strength at $0.2 \%$ when the materials exhibited a ductile behaviour.

vacuum atmosphere, most likely due to the porosity decreasing the alloy cohesion. The DBTT was defined as when the $\sigma-\varepsilon$ curves changed their behaviour from linearly elastic to plastic. An improvement was observed upon the refinement of the grain size, as the DBTT of $\mathrm{W}$-2Ti after $75 \mathrm{~h} \mathrm{MA}$, was above $800^{\circ} \mathrm{C}$. This alloy appears to exhibit better bending strengths at low temperature than corresponding strengths reported for the W-4Ti alloy, which did not show plastic deformation up to $1000^{\circ} \mathrm{C}$ [33].

Fig. 5 shows the temperature effect on the bending behaviour of the alloys. The stress-strain curves for $\mathrm{W}-1 \mathrm{TiC}$ reveal plastic deformation only at $1200^{\circ} \mathrm{C}$ and completely brittle behaviour at lower temperatures. The $\mathrm{W}-5 \mathrm{TiC}$ alloy exhibits plastic deformation at $1000^{\circ} \mathrm{C}$ and an entirely brittle behaviour at $\mathrm{T} \leq 1000^{\circ} \mathrm{C}$.

When comparing pure tungsten with $\mathrm{W}$-TiC alloys average bending strength, it can be perceived that the flexural strength exhibited an increase over room temperature levels as the test temperature increased, except in the pure $\mathrm{W}$ sample, as shown in Fig. 6. Strength decreased with further increasing test temperature from 800 to $1200^{\circ} \mathrm{C}$. On the contrary, the strength of pure $\mathrm{W}$ always decreased with increasing temperature. $\mathrm{W}-5 \mathrm{TiC}$ possessed the highest strength value of $\sim 900 \mathrm{MPa}$ at $800^{\circ} \mathrm{C}$. However, DBTT is still up to $1000^{\circ} \mathrm{C}$.

The addition of $\mathrm{TiC}$ particles to tungsten matrix is beneficial to mechanical properties of $\mathrm{W}$. These secondary phase particles

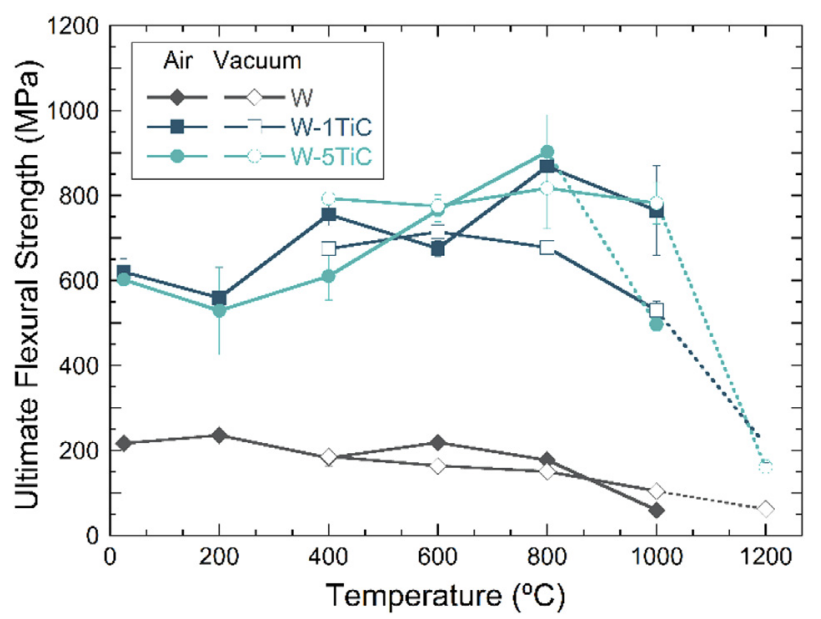

Fig. 6. Flexural strength versus temperature for $\mathrm{W}-1 \mathrm{TiC}$ and $\mathrm{W}-5 \mathrm{TiC}$ alloys and pure W. The error bars correspond to the standard deviation of the experimental data. The dashed lines indicate the region where ductile behaviour was observed, hence $0.2 \%$ yield strength is represented.

usually remain (though high resolution TEM analysis should be necessary to ensure this hypothesis) in the grain boundaries. Usually, because of their high modulus, the strengthening particles will carry more stress than tungsten matrix when suffering the same strain, since they have good interface joint with adjacent tungsten matrices. This assures the load transferring to TiC particles when loading. The load transferring mechanism is an important strengthening mechanism.

These results are in good agreement with the ones reported by Song [34] for TiC particle-reinforced tungsten based composites but slightly lower than those reported by Ref. [35] of $1065 \mathrm{MPa}$ for an alloy containing $1 \mathrm{wt} \% \mathrm{TiC}$ processed by MA as well.

Furthermore, it should be noted that the bending strength at $1100{ }^{\circ} \mathrm{C}$ for other $\mathrm{W}$ alloys processed by the same route is noticeably lower: around $300 \mathrm{MPa}$ for pure $\mathrm{W}$ and around $350 \mathrm{MPa}$ for ODS $\mathrm{W}-2 \mathrm{Ti}-0.5 \mathrm{Y}_{2} \mathrm{O}_{3}$ and $\mathrm{W}-4 \mathrm{Ti}-0.5 \mathrm{Y}_{2} \mathrm{O}_{3}[20,22]$. Therefore, it can be stated that small amounts of $\mathrm{TiC}$ can enhance the thermomechanical performance of pure $\mathrm{W}$.

The fracture toughness tests showed brittle behaviour in all the temperature range tested for both atmospheres (Fig. 7). The addition of $\mathrm{Ti}$ in the tungsten matrix promotes the toughening of the alloy for all the temperatures studied, showing approximately an improvement of 3 and $1 \mathrm{MPam}^{1 / 2}$, after $75 \mathrm{~h}$ and $20 \mathrm{hMA}$
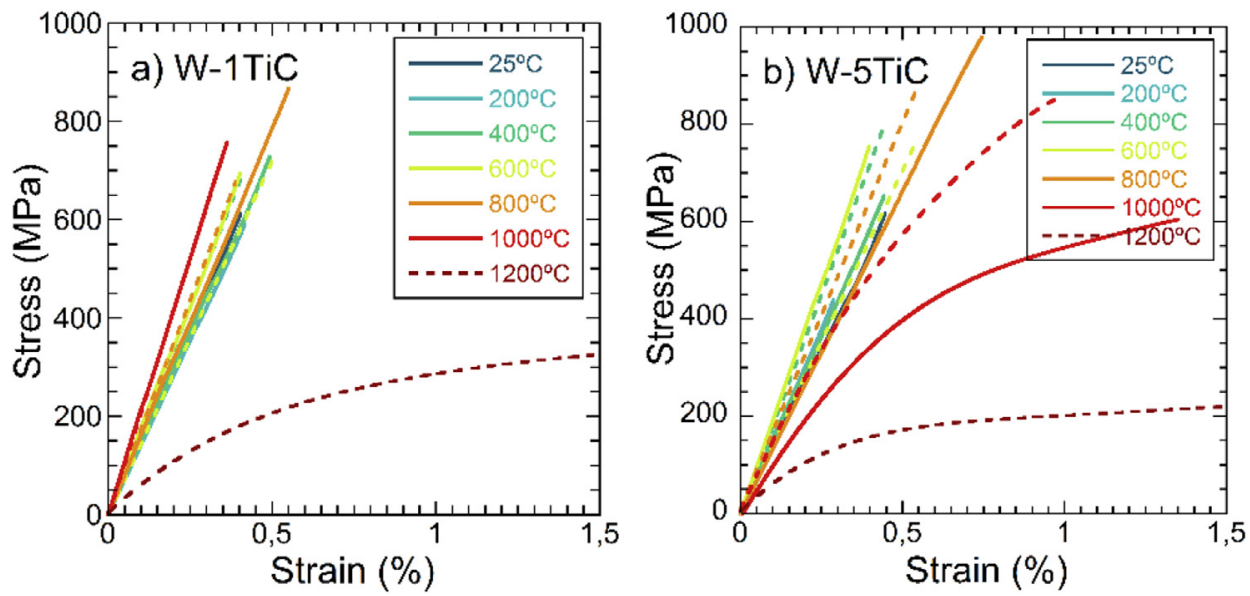

Fig. 5. Stress versus strain curves after TPB tests for (a) W-1TiC alloy and (b) W-TiC alloy. Dashed lines indicate tests performed under a high vacuum atmosphere. 


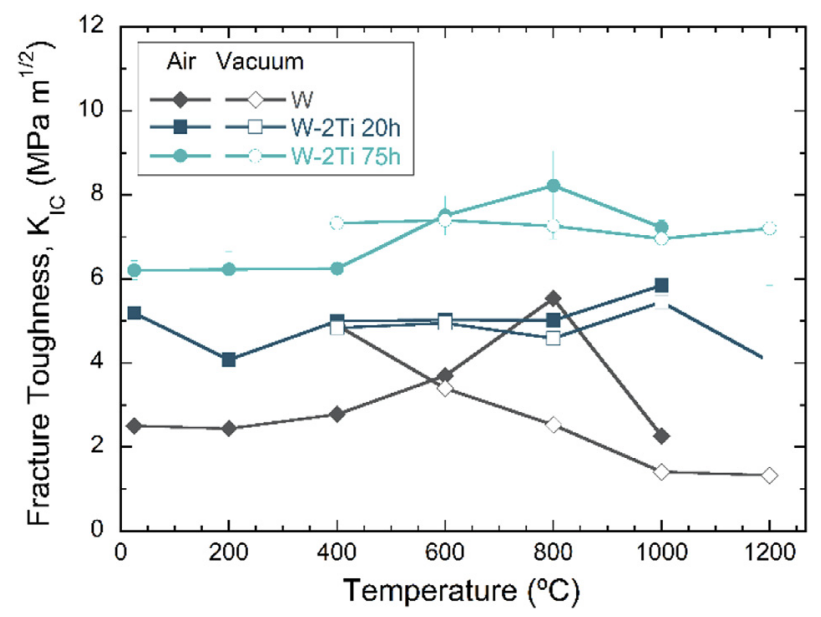

Fig. 7. Nominal fracture toughness of W-2Ti alloys and pure $\mathrm{W}$ tested as a function of temperature. The error bars correspond to the standard deviation of the experimental data.

respectively, as compared to our pure $\mathrm{W}$ produced under the same conditions as the rest of the materials. The homogenization and refinement of the microstructure after $75 \mathrm{~h} \mathrm{MA}$ lead to higher values of $\mathrm{K}_{\mathrm{IC}}$ as defects, i.e. large non-milled $\mathrm{W}$ particles, may act as stress concentrators for the fracture. Values obtained at ambient atmosphere are slightly higher than those obtained in vacuum. However, this improvement of the values was attributed to the possible blunting of the surface defects due to superficial oxide formation.

The toughness of W-TiC alloys as a function of temperature was assessed from three-point bending on notched bars. They are plotted in Fig. 8, together with the results corresponding to the pure W. For W-1TiC, the load-displacement curves were linear until fracture in the whole temperature range. W-5TiC exhibited this performance up to $1000^{\circ} \mathrm{C}$ when slight plastic behaviour was observed (represented as dashed lines in the graph). Thus, the stress intensity factor loses its validity with increasing ductile behaviour and the calculated values give only a lower bound of fracture toughness. The evolution of $\mathrm{K}_{\mathrm{IC}}$ with temperature for $\mathrm{W}$ $1 \mathrm{TiC}$ is comparable with that observed for pure $\mathrm{W}$ in air atmosphere

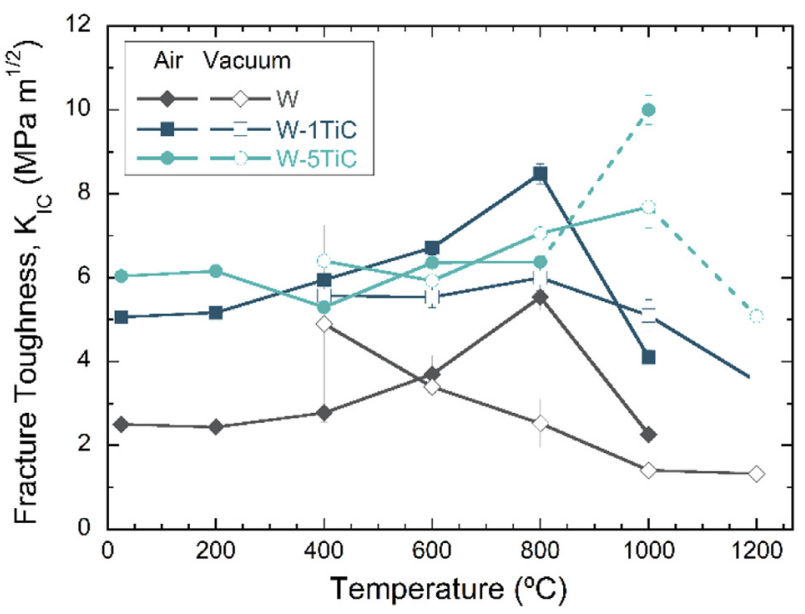

Fig. 8. Fracture toughness versus temperature for $\mathrm{W}-1 \mathrm{TiC}$ and $\mathrm{W}-5 \mathrm{TiC}$ alloys and pure $W$. The error bars correspond to the standard deviation of the experimental data. The dashed lines indicate the region where linear elastic fracture mechanics is no longer valid. as it shows better performance in air than in vacuum. This is probably due to the growth of superficial oxidation that contributes to the blunting of the superficial defects causing an apparent increase in the values. On the contrary, no such differences can be extracted from $\mathrm{W}-5 \mathrm{TiC}$ performance, since its values are overlapped in all the temperature range. Thus, it seems that TiC may act as oxidation inhibitor; this effect will be explained with more details in the fractographical analysis.

\subsection{Fractographical analysis}

W-2Ti materials presented brittle inter-granular fracture, due to the decohesion among $\beta(\mathrm{W}-\mathrm{Ti})$ particles, and cleavage of large $\mathrm{W}$ particles, typical of BCC metals. These results supported the brittle behaviour observed during the fracture tests and maintained up to temperatures below $800^{\circ} \mathrm{C}$.

Regarding the testing atmosphere, no passivation effect can be attributed to Ti alloying, after either $20 \mathrm{~h}$ or $75 \mathrm{~h} \mathrm{MA}$. At $400^{\circ} \mathrm{C}$ oxidation is clearly visible on the fracture surfaces of both alloys (Fig. 9b) and at $600^{\circ} \mathrm{C}$ samples are entirely covered by a tungsten oxides layer (Fig. 9c).

It has been reported that the addition of Ti can moderately enhance the strength and fracture toughness of $\mathrm{W}$ in all the temperature range tested. However, these results did not show an apparent decrease of the DBTT as compared to pure W. Even although the present processing conditions appear to develop particle dispersion and fine grain structure, especially after $75 \mathrm{~h}$ milling time. This result could be associated with Ti segregation at the grain boundaries. Furthermore, a non-negligible $\mathrm{O}_{2}$ concentration is also present in the alloys, which may also be segregated at the grain boundaries forming complex oxides. The segregated phases may develop a high concentration of internal stresses in the grain boundaries promoting the grain boundary decohesion and brittleness of the alloys, as it occurs in Mo alloys [36]. Furthermore, the performance of these alloys under a possible loss of vacuum inside the reactor is quite similar to the exhibited by pure tungsten.

On the other hand, morphological features of the fracture surfaces of $\mathrm{W}$-TiC materials tested at room temperature are shown in Fig. 10, the size of $\mathrm{W}$ grains in the $\mathrm{W}-5 \mathrm{TiC}$ material $\mathrm{W}$ is significantly smaller than that of W-1TiC. This is due to the addition of TiC particles, which inhibits the growth of $\mathrm{W}$ grains during the sintering process.

However, with higher content of TiC and MA times, small grains alignment has been observed (Fig. 11a), while large $\mathrm{W}$ grains remain un-milled (Fig. 11b).

Morphologies of fracture surface of both W-TiC materials are similar: the fracture surface displays a typical brittle fracture mixing of intergranular rupture of small grains with transgranular cleavage fracture on larger $\mathrm{W}$ grains. Even with the addition of strengthening particles, grain boundaries are weaker than the grain interior and this effect is maintained at higher temperatures as observed in Fig. 12 for $\mathrm{W}-1 \mathrm{TiC}$ tested at $800^{\circ} \mathrm{C}$. However, the high density of grain boundaries contributes to the crack deflection. It might result from the secondary strengthening particles. These particles, with high hardness and modulus, will deflect the crack propagation path. The more flexuous the crack propagation path, the higher the fracture toughness due to energy consumption during deflection.

Although the melting point of both $\mathrm{W}$ and $\mathrm{TiC}$ is over $3000^{\circ} \mathrm{C}$, strong degradation of the materials can be observed after testing at $1200{ }^{\circ} \mathrm{C}$ (see Fig. 13). Reactivity of W with carbon is very high hence WC compounds may be sintered during the heating process [37].

As shown in test results, the primary benefit of adding $5 \mathrm{wt} \% \mathrm{TiC}$ is the increase in the values of flexural strength and fracture toughness of the alloy. However, a secondary benefit can be 

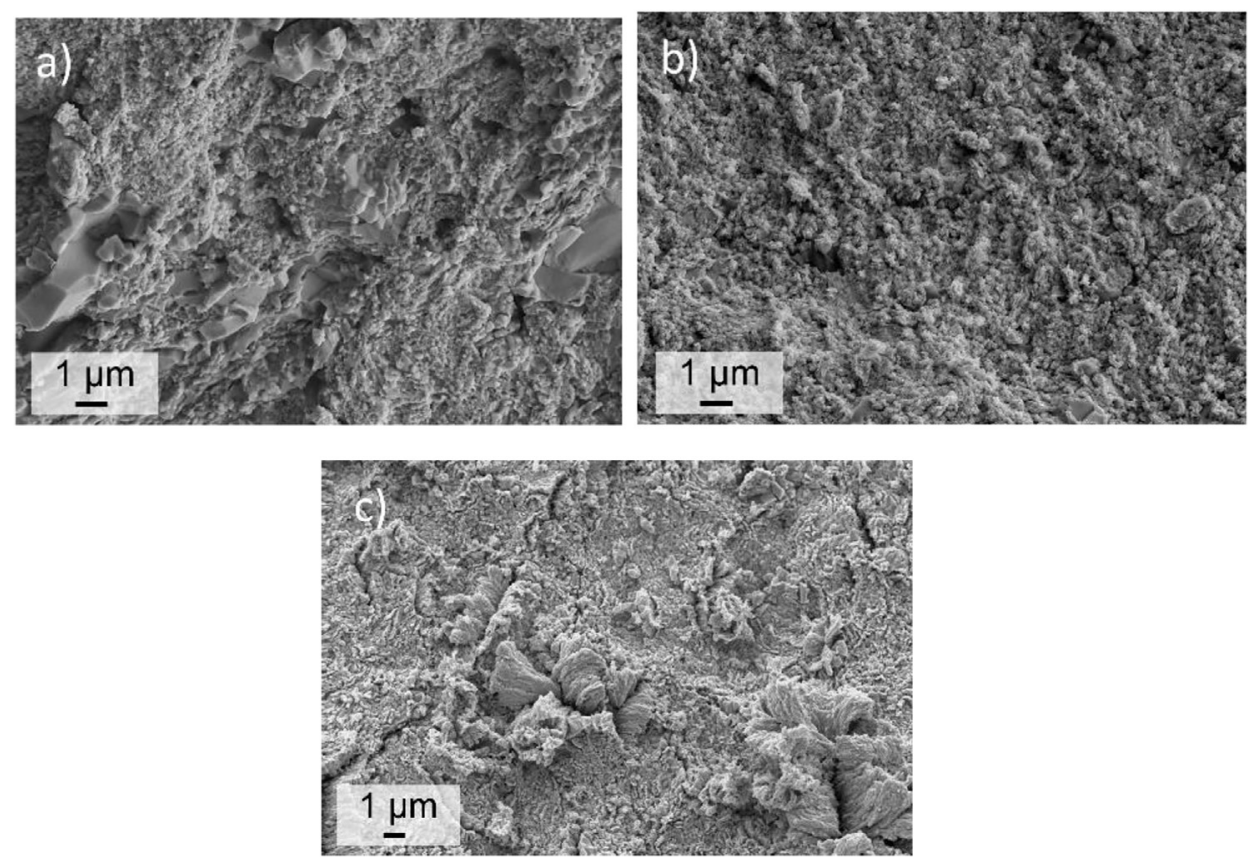

Fig. 9. SEM tractography of W-2Ti alloys tested at (a) $200^{\circ} \mathrm{C}(20 \mathrm{~h} \mathrm{MA})$, (b) $400^{\circ} \mathrm{C}(75 \mathrm{~h} \mathrm{MA})$ and $600^{\circ} \mathrm{C}(20 \mathrm{~h} \mathrm{MA})$ in TPB configuration and under ambient atmosphere.
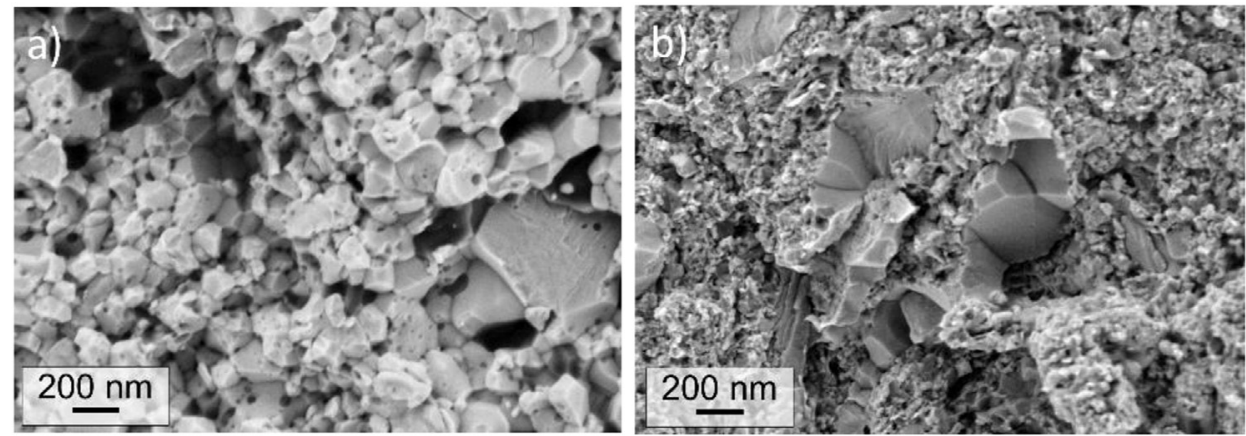

Fig. 10. Fracture surfaces of (a) W-1TiC and (b) W-5TiC tested at $25^{\circ} \mathrm{C}$ in TPB.
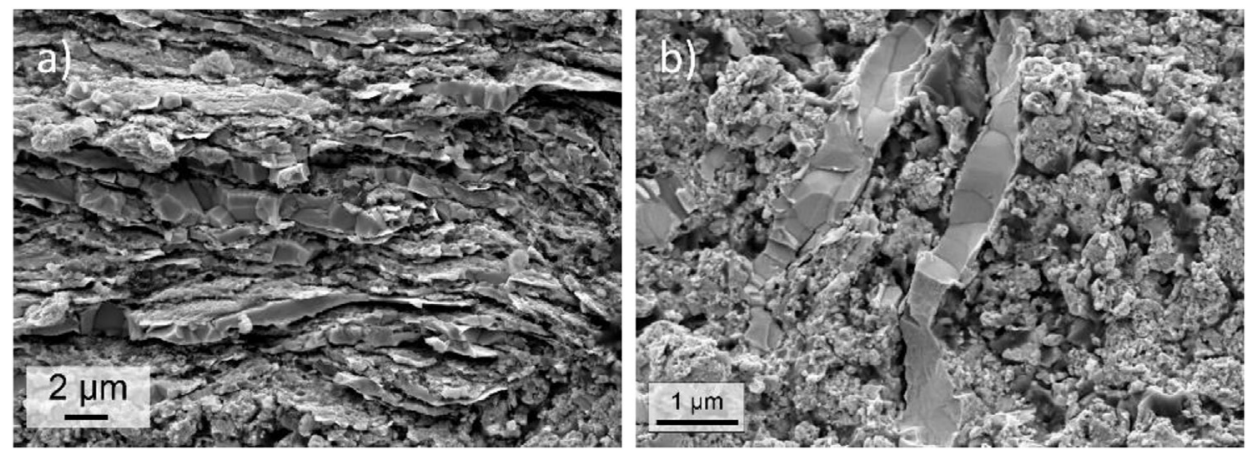

Fig. 11. Fracture surfaces of $\mathrm{W}-5 \mathrm{TiC}$ tested at $400^{\circ} \mathrm{C}$ in vacuum atmosphere. Alignment of small grains (a)and large $\mathrm{W}$ particles (b) can be appreciated.

attributed to the addition of TiC: oxide formation is inhibited up to $600^{\circ} \mathrm{C}$, as shown in the fracture surfaces of $\mathrm{W}-1$ TiC after testing at 400,600 and $800^{\circ} \mathrm{C}$ in air (Fig. 14a, b, and c, respectively). With regards to the latter, it should be mentioned again that at $400{ }^{\circ} \mathrm{CW}$ -
2Ti alloys (Fig. 9) and pure W [25] are covered by an oxidation layer. The results show that strengthening particles mostly existing at grain boundaries inhibit the growth of tungsten grains in the sintering process. The $\mathrm{W}$-TiC composites have an average nanometric 


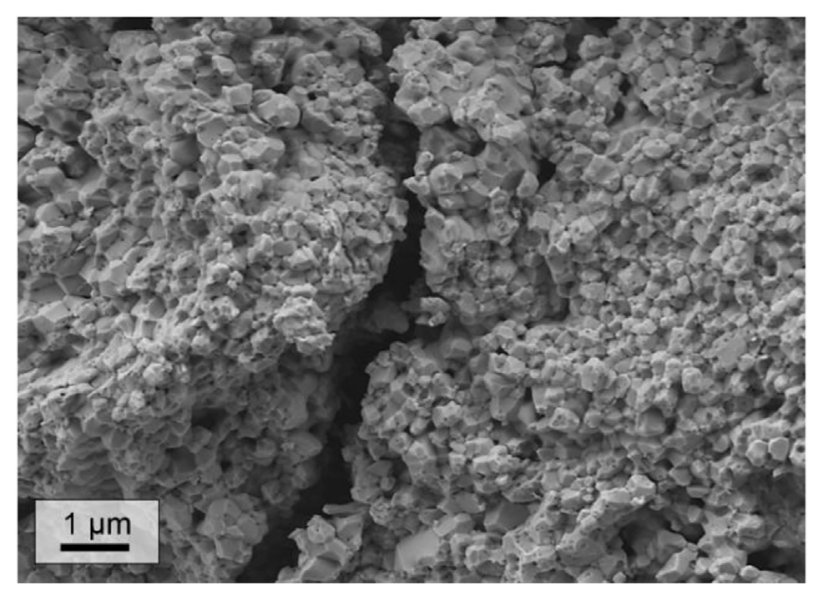

Fig. 12. Fracture surface of $\mathrm{W}-1 \mathrm{TiC}$ tested at $800^{\circ} \mathrm{C}$ under vacuum atmosphere.

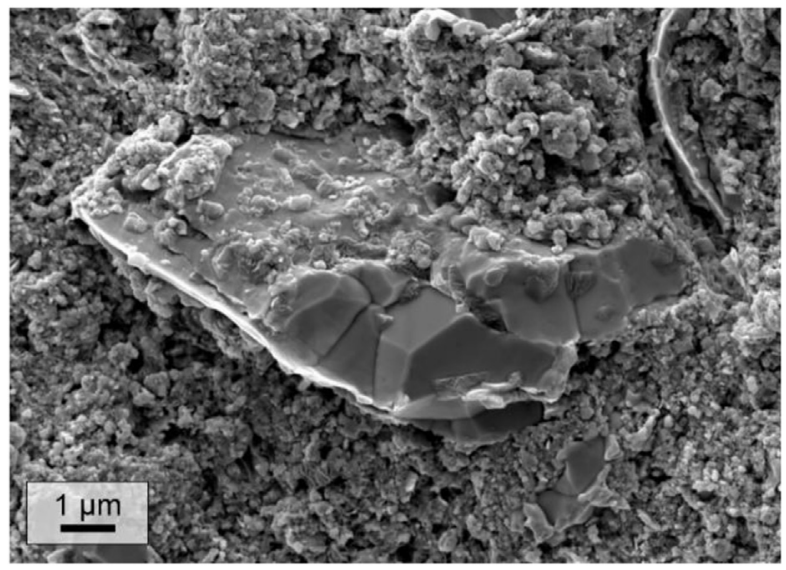

Fig. 13. Fracture surface of $\mathrm{W}-5 \mathrm{TiC}$ tested at $1200^{\circ} \mathrm{C}$ under vacuum atmosphere.

grain size, and the fine grains are helpful to improve the strength and toughness of composites. The maximum of flexural strength and fracture toughness are $900 \mathrm{MPa}$ and $8.5 \mathrm{MPa} \mathrm{m}^{1 / 2}$, respectively corresponding to the alloy $\mathrm{W}-1 \mathrm{TiC}$ at $800^{\circ} \mathrm{C}$, although similar results were presented by $\mathrm{W}-5 \mathrm{TiC}$.

However, per values obtained from the TPB tests, these W-1TiC and $\mathrm{W}-5 \mathrm{TiC}$ alloys have the ductile-brittle transition above $1000^{\circ} \mathrm{C}$, which is higher than that of pure W. TiC hard particles strongly constrain the plastic behaviour of the $\mathrm{W}$ matrix by hindering dislocation movement. Ishijima [38] attributed the detrimental effect on the ductility to the following three microstructural factors: (1) precipitation of the brittle $\mathrm{W}_{2} \mathrm{C}$ phase, (2) heterogeneity in grain size and particle distributions and (3) significant loss of carbon necessary for the formation of finely dispersed particles of transition metal carbides.

\section{Conclusions}

The main requirements of tungsten materials for structural divertor applications comprise properties like high thermal conductivity, high-temperature strength and stability and high recrystallization temperature, among others. However, the brittleness of tungsten commercial products is still the main concern for their use in structural armour applications. In this regard, in the present paper, two general ductilisation strategies were followed: (1) alloying to produce a solid solution with Ti and (2) maintaining a UFG microstructure adding TiC dispersed particles, both with the aim of obtaining a suitable fusion armour material with enhanced properties.

The effect of the MA duration during the processing route was studied and tried to be optimized to attain UFG microstructures. Increasing the milling time lead to a decrease and homogenization of the grain size. However, the beneficial effects of this refinement was narrowed by the $\mathrm{O}_{2}$ contamination during the process $\mathrm{W}-2 \mathrm{Ti}$ materials.

It has been reported that the addition of $\mathrm{Ti}$ and $\mathrm{TiC}$ can enhance the strength and fracture toughness of $\mathrm{W}$ in all the temperature range tested, as $\mathrm{TiC}$ in the grain boundaries presumably acted as grain growth inhibitors. Furthermore, both flexural strength and fracture toughness were twice and even three times higher than the ones observed for our reference pure tungsten, which is, indeed, a great success.

However, these results did not show an apparent decrease of the DBTT as compared to our reference pure W. Even although the present processing conditions appear to develop a particle dispersion and fine grain structure, especially after $75 \mathrm{~h}$ milling time for $\mathrm{W}$-2Ti alloy. This result could be associated with Ti segregation at the grain boundaries. Furthermore, a non-negligible $\mathrm{O}_{2}$ concentration is also present in the alloys, which may also be segregated at the grain boundaries forming complex oxides. These segregated phases would develop a high concentration of internal stresses in the grain boundaries promoting decohesion and brittleness of the alloys, as it occurs in Mo alloys [36]. Furthermore, the performance of these alloys under a possible loss of vacuum inside the reactor is quite similar to the exhibited by pure tungsten.

\section{Data availability}

The raw and processed data required to reproduce these findings will be made available on request.
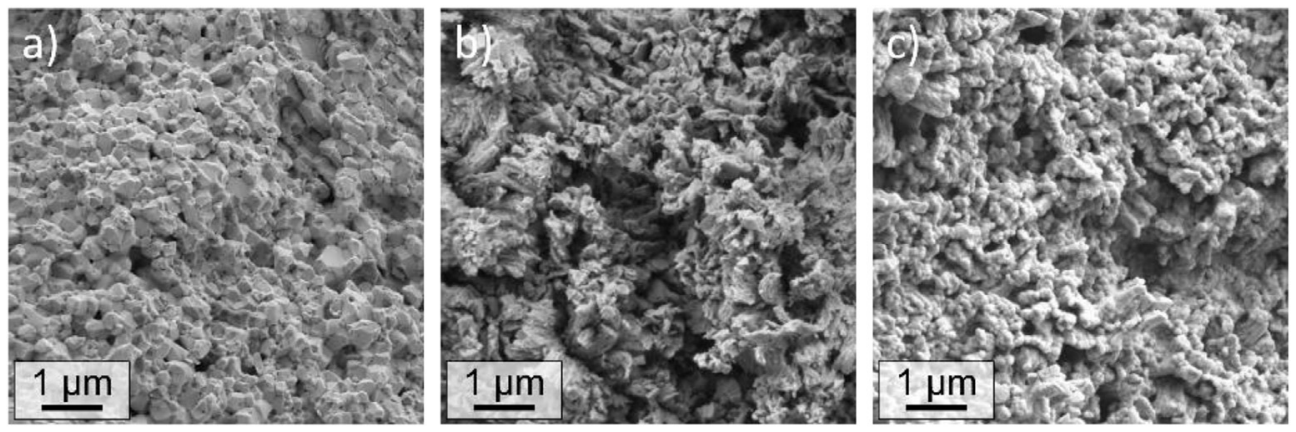

Fig. 14. SEM fractographic surfaces of $\mathrm{W}-1 \mathrm{TiC}$ material tested in TPB at a) $400^{\circ} \mathrm{C}$, b) $600{ }^{\circ} \mathrm{C}$ and c) $800^{\circ} \mathrm{C}$, tested in air. 


\section{Acknowledgements}

The authors would like to thank the Physics Department and especially Dr Muñoz and Dr Monge, of the Carlos III University (Leganés, Spain) for providing the materials under study.

This work has been carried out within the framework of the EUROfusion Consortium and has received funding from the EURATOM research and training programme 2014-2018 under grant agreement No 633053. The views and opinions expressed herein do not necessarily reflect those of the European Commission.

The authors also acknowledge the support of the Ministerio de Economía y Competitividad of Spain (research project MAT201570780-C4-4-P) and the Comunidad de Madrid (research project S2013/MIT-2862-MULTIMATCHALLENGE) who have funded this research.

\section{References}

[1] M. Rieth, S.L. Dudarev, S.M. Gonzalez de Vicente, J. Aktaa, T. Ahlgren, S. Antusch, D.E.J. Armstrong, M. Balden, N. Baluc, M.-F. Barthe, W.W. Basuki, M. Battabyal, C.S. Becquart, D. Blagoeva, H. Boldyryeva, J. Brinkmann, M. Celino, L. Ciupinski, J.B. Correia, A. De Backer, C. Domain, E. Gaganidze, C. García-Rosales, J. Gibson, M.R. Gilbert, S. Giusepponi, B. Gludovatz, H. Greuner, K. Heinola, T. Höschen, A. Hoffmann, N. Holstein, F. Koch, W. Krauss, H. Li, S. Lindig, J. Linke, C. Linsmeier, P. López-Ruiz, H. Maier, J. Matejicek, T.P. Mishra, M. Muhammed, A. Muñoz, M. Muzyk, K. Nordlund, D. Nguyen-Manh, J. Opschoor, N. Ordás, T. Palacios, G. Pintsuk, R. Pippan, J. Reiser, J. Riesch, S.G. Roberts, L. Romaner, M. Rosiński, M. Sanchez, W. Schulmeyer, H. Traxler, A. Ureña, J.G. van der Laan, L. Veleva, S. Wahlberg, M. Walter, T. Weber, T. Weitkamp, S. Wurster, M.A. Yar, J.H. You, A. Zivelonghi, Recent progress in research on tungsten materials for nuclear fusion applications in Europe, J. Nucl. Mater. 432 (2013) 482-500.

[2] R. Wenninger, R. Kemp, F. Maviglia, H. Zohm, R. Albanese, R. Ambrosino, DEMO exhaust challenges beyond ITER, in: 42nd EPS Conf. Plasma Phys, 2015.

[3] G. Federici, R. Kemp, D. Ward, C. Bachmann, T. Franke, S. Gonzalez, C. Lowry, M. Gadomska, J. Harman, B. Meszaros, C. Morlock, F. Romanelli, R. Wenninger, Overview of EU DEMO design and R\&D activities, Fusion Eng. Des. 89 (2014) 882-889.

[4] H. Zohm, From ITER to DEMO, in: The Physics of ITER, Presentation, DPG Advanced Physics School, 2014.

[5] J.W. Davis, V.R. Barabash, A. Makhankov, L. Plöchl, K.T. Slattery, Assessment of tungsten for use in the ITER plasma facing components, J. Nucl. Mater. 258-263 (1998) 308-312.

[6] D. Stork, P. Agostini, J.L. Boutard, D. Buckthorpe, E. Diegele, S.L. Dudarev, C. English, G. Federici, M.R. Gilbert, S. Gonzalez, A. Ibarra, C. Linsmeier, A. Li Puma, G. Marbach, P.F. Morris, L.W. Packer, B. Raj, M. Rieth, M.Q. Tran, D.J. Ward, S.J. Zinkle, Developing structural, high-heat flux and plasma facing materials for a near-term DEMO fusion power plant: the EU assessment, J. Nucl. Mater. 455 (2014) 277-291.

[7] T. Palacios, J. Reiser, J. Hoffmann, M. Rieth, A. Hoffmann, J.Y. Pastor, Microstructural and mechanical characterization of annealed tungsten (W) and potassium-doped tungsten foils, Int. J. Refract. Metals Hard Mater. 48 (2015) $145-149$.

[8] V.P. Budaev, Y.V. Martynenko, A.V. Karpov, N.E. Belova, A.M. Zhitlukhin, N.S. Klimov, V.L. Podkovyrov, V.A. Barsuk, A.B. Putrik, A.D. Yaroshevskaya, R.N. Giniyatulin, V.M. Safronov, L.N. Khimchenko, Tungsten recrystallization and cracking under ITER-relevant heat loads, J. Nucl. Mater. 463 (2015) 237-240.

[9] J. Linke, High heat flux performance of plasma facing materials and components under service conditions in future fusion reactors, Trans. FUSION Sci. Technol. 53 (2008) 10

[10] A. Calvo, N. Ordás, I. Iturriza, J.Y. Pastor, E. Tejado, T. Palacios, C. Garca-Rosales, Manufacturing of self-passivating tungsten based alloys by different powder metallurgical routes, Phys. Scripta T167 (2016), 014041, 6.

[11] E. Lassner, W.-D. Schubert, Tungsten: Properties, Chemistry, Technology of the Element, Alloys, and Chemical Compounds, Kluwer Academic/Plenum Publishers, 1999.

[12] Y. Mutoh, K. Ichikawa, K. Nagata, M. Takeuchi, Effect of rhenium addition on fracture toughness of tungsten at elevated temperatures, J. Mater. Sci. 30 (1995) 770-775.

[13] A. Luo, D.L. Jacobson, K.S. Shin, Solution softening mechanism of iridium and rhenium in tungsten at room temperature, Int. J. Refract. Metals Hard Mater 10 (1991) 107-114.

[14] F. Rowcliffe, Tungsten-based Materials for Divertor Applications, n.d.

[15] C. Yin, D. Terentyev, T. Pardoen, A. Bakaeva, R. Petrov, S. Antusch, M. Rieth, M. Vilémová, J. Matějiček, T. Zhang, Tensile properties of baseline and advanced tungsten grades for fusion applications, Int. J. Refract. Metals Hard Mater. 75 (2018) 153-162.

[16] M. Faleschini, H. Kreuzer, D. Kiener, R. Pippan, Fracture toughness investigations of tungsten alloys and SPD tungsten alloys, J. Nucl. Mater 367-370 (2007) 800-805.

[17] J. Fan, Y. Han, P. Li, Z. Sun, Q. Zhou, Micro/nano composited tungsten materia and its high thermal loading behavior, J. Nucl. Mater. 455 (2014) 717-723.

18] X. Tan, P. Li, L. Luo, Q. Xu, K. Tokunaga, X. Zan, Y. Wu, Effect of second-phase particles on the properties of $\mathrm{W}$-based materials under high-heat loading, Nucl. Mater. Energy. 9 (2016) 399-404.

[19] M. Fukuda, A. Hasegawa, T. Tanno, S. Nogami, H. Kurishita, Property change of advanced tungsten alloys due to neutron irradiation, J. Nucl. Mater. 442 (2013) S273-S276

[20] T. Palacios, J.Y. Pastor, M.V. Aguirre, M.A. Monge, R. Pareja, Mechanica behaviour of tungsten-vanadium-lanthana alloys as function of temperature, J. Nucl. Mater. 442 (2013) S277-S281.

[21] M.V. Aguirre, A. Martín, J.Y. Pastor, J. Llorca, M.A. Monge, R. Pareja, Mechanical properties of tungsten alloys with Y2O3 and titanium additions, J. Nucl. Mater 417 (2011) 516-519.

[22] M.V. Aguirre, A. Martín, J.Y. Pastor, J. Llorca, M.A. Monge, R. Pareja, Mechanical properties of Y2O3-doped W-Ti alloys, J. Nucl. Mater. 404 (2010) 203-209.

[23] S. Jonsson, Reevaluation of the Ti-W system and prediction of the Ti-W-N phase diagram, Mater. Res. Adv. Tech. 87 (1996) 784-787.

[24] H. Li, S. Wurster, C. Motz, L. Romaner, C. Ambrosch-Draxl, R. Pippan, Dislocation-core symmetry and slip planes in tungsten alloys: Ab initio calculations and microcantilever bending experiments, Acta Mater. 60 (2012) 748-758.

[25] T. Palacios, A. Jiménez, A. Muñoz, M.A. Monge, C. Ballesteros, J.Y. Pastor, Mechanical characterisation of tungsten-1 wt.\% yttrium oxide as a function of temperature and atmosphere, J. Nucl. Mater. 454 (2014) 455-461.

[26] T. Palacios, J.Y. Pastor, Influence of the notch root radius on the fracture toughness of brittle metals: nanostructure tungsten alloy, a case study, Int. J. Refract. Metals Hard Mater. 52 (2015) 44-49.

[27] J.Y. Pastor, G.V. Guinea, J. Planas, M. Elices, Nueva expresión del factor de intensidad de tensiones para la probeta de flexión en tres puntos, An. Mecánica la Fract. 12 (1995) 296-301.

[28] G.V. Guinea, J.Y. Pastor, J. Planas, M. Elices, Stress intensity factor, compliance and CMOD for a general three-point-bend beam, Int. J. Fract. 89 (1998) 103-116.

[29] ASM International. Handbook committee., ASM Handbook Vol 2: Properties and Selection: Nonferrous Alloys and Special-purpose Materials, n.d.

[30] Y. Chen, Y.C. Wu, F.W. Yu, J.L. Chen, Microstructure and mechanical properties of tungsten composites co-strengthened by dispersed TiC and La2O3 particles Int. J. Refract. Metals Hard Mater. 26 (2008) 525-529.

[31] H. Jahangiri, M.L. Öveçoğlu, Determination of crystallite size, strain and solubility in mechanically alloyed $\mathrm{W}$-xTi $(\mathrm{x}=0.5,1.0,4.0$ and $10.0 \mathrm{wt} \%)$ powder alloys, Mater. Lett. 178 (2016) 193-196.

32] B. Savoini, J. Martinez, A. Muñoz, M.A. Monge, R. Pareja, Microstrucutre an temperature dependance of the microhardness of W-4V-1La2O3 and W-4Ti1La2O3, J. Nucl. Mater. 442 (2013) S229-S232.

33] M.V. Aguirre, A. Martín, J.Y. Pastor, J. Llorca, M.A. Monge, R. Pareja, Mechanical behavior of $\mathrm{W}-\mathrm{Y} 2 \mathrm{O} 3$ and $\mathrm{W}$-Ti alloys from $25{ }^{\circ} \mathrm{C}$ to $1000{ }^{\circ} \mathrm{C}$, Metall. Mater. Trans. 40 (2009) 2283-2290.

[34] G.-M. Song, Y.-J. Wang, Y. Zhou, Thermomechanical properties of TiC particlereinforced tungsten composites for high temperature applications, Int. J. Refract. Metals Hard Mater. 21 (2003) 1-12.

[35] F. Chong, F. Yu, J. Chen, W-TiC alloy plasma facing materials and heat flux performance test under electron beam FacilityNo title, Rare Metal Mater. Eng. 39 (2010) 750-752.

[36] G. Liu, G.J. Zhang, F. Jiang, X.D. Ding, Y.J. Sun, J. Sun, E. Ma, Nanostructured high-strength molybdenum alloys with unprecedented tensile ductility, Nat Mater. 12 (2013) 344-350.

[37] J.R. Davis, ASM International. Handbook Committee: Tool Materials, ASM International, 1995

[38] Y. Ishijima, H. Kurishita, H. Arakawa, M. Hasegawa, Y. Hiraoka, T. Takida, K. Takebe, Microstructure and bend ductility of $\mathrm{W}-0.3$ mass\%TiC alloys fabricated by advanced powder-metallurgical processing, Mater. Trans. 46 (2005) 568-574. 